\title{
EFFECT OF SINGLE DOSE ORAL ISOSORBIDE DINITRATE TABLETS ON THE INTRAOCULAR PRESSURE
}

\author{
BY \\ *MEGWAS, A. U. AND EMEREOLE, C. A. E. \\ DEPARTMENT OF OPTOMETRY, \\ IMO STATE UNIVERSITY, OWERRI NIGERIA \\ Email:tonymegwas@yahoo.com \\ *Corresponding author
}

\begin{abstract}
The effect of isosorbide dinitrate (ISORDIL ${ }^{\circledR}$ ) on intraocular pressure (IOP) was studied using rabbits as experimental animals. There was a net decrease in IOP following administration of the drug. The study rabbits were divided into 2 groups (the $10 \mathrm{mg}$ per day group and the $20 \mathrm{mg}$ per day group) of 4 rabbits each. The initial IOP was taken before administration of the drug. The first group was given $1 \mathrm{ml}$ of $10 \mathrm{mg} / \mathrm{ml}$ solution of the drug orally, once daily for five days and the second group received same regimen orally, but was given $2 \mathrm{ml}$ of the $10 \mathrm{mg} / \mathrm{ml}$ solution. The IOP was monitored for seven days using Schiotz indentation tonometer. Statistical analysis using ANOVA showed significant difference $(\mathrm{P}>0.05)$ between the means of various days in the second group. There was no significant difference $(\mathrm{P}<0.05)$ between the means of various days in the first group. It can be inferred from the study that ISORIDIL ${ }^{\circledR}$ has no threatening effect on the ocular integrity if taken at normal does but one should guide against overdose as it might significantly raise the IOP.
\end{abstract}

KEYWORDS: Isosorbide dinitrate, Intraocular pressure, Congestive cardiac condition, Angina pectoris, Nitric oxide.

\section{INTRODUCTION}

Generally the world over, glaucoma has remained an increasingly disturbing cause of blindness especially when undetected earlier. Originally, glaucoma was thought to result solely from an increase in ocular tension which is clinically significant when the pressure rises above $21 \mathrm{mmHg}^{1}$. However, it is a well-established fact that glaucoma could develop or persist despite normal or low ocular tensions, conditions which have been clinically described as normal tension or low tension glaucoma respectively. The pathogenesis of both the normal tension and low tension glaucoma is gradual decrease in vascular perfusion to the optic nerve head that results in glaucomatous atrophy despite a normal intraocular pressure.

Isosorbide dinitrate (ISDN), being an organic nitrate and a vasodilator, affects both arteries and veins with a preponderant effect on the veins. This white crystalline odorless compound with a chemical nomenclature of $1,4: 3,6$ dianhydrosorbitol 2,5-dinitrate is an important cardiotherapeutic agent used in the management and treatment of congestive cardiac condition including angina pectoris. Its effects are mediated by its active moiety isosorbide-5-mononitrate. The principal pharmacological effect of isosorbide-5- mononitrate is relaxation of vascular smooth muscles and the consequent dilation of peripheral arteries and veins especially the latter. In humans, isosorbide-5-mononitrate is not subject to significant first pass metabolic changes in the liver. The absolute bioavailability of isosorbide-5mononitrate from tablets is nearly $100 \%$. The absorption is rapid, and maximum.

Serum concentrations are achieved 30-60 minutes after dosing. The overall elimination halflife is about 5 hours and the rate of clearance is the same in healthy young adults, and in the elderly. ISDN may also serve to increase vascular perfusion to the optic nerve head ${ }^{2,3 .}$

ISDN is member of the nitric oxide (NO) group of drugs, which medicate their pharmacotherapeutic nitrates ${ }^{4} \mathrm{NO}$ has also been established to be a mediator of physiologic and pathologic processes in the eye, for example regulation of aqueous humor dynamics, vascular tone, retinal neurotransmission, retinal ganglion cell death by apoptosis, phototransduction and ocular immunological responses ${ }^{5.67 .}$. Hence, both an overproduction and underproduction of $\mathrm{NO}$ may contribute to pathological processes in degenerative diseases (uveitis, retinitis) in the eye $^{5,8,}$ and may have effects on the development and progression of glaucoma'. NO also has a 
vasodilatory function for blood flow in the optic nerve head ${ }^{10}$, causing researchers to propose nitro vasodilators as possible ocular hypertensive agent $^{11}$.

NO seem to be implicated in the regulation of intraocular pressure (IOP). In the anterior segment of the eye, NO donors or nitro vasodilators may regulate IOP at the level of ciliary's muscle, trabecular meshwork and endothelial and vascular smooth muscle cells in the aqueous drainage system $^{5,7,10,12}$. Again, nitrergic nerves might dilate episcleral vessels, thereby lowering episcleral venous pressure and further the resistance to aqueous humour out flows, leading to decreased $\mathrm{IOP}^{10}$. In addition, it has been hypothesized that NO or nitric oxide-derived radicals might result in neurotoxic glaucomatous effects at the optic nerve head and retina, leading to optic nerve head degeneration and visual field loss ${ }^{13}$.

Although ISDN is very effective in cardiovascular therapy, suspicions are held concerning its effect on the ocular system. Because the drug is non-selective in its action and since the ocular integrity is to a large extent dependent on the quality and quantity of blood flow to the eye as is related to systemic changes, this research work thus emphasizes on the nitric oxide-donor action of ISDN, to investigate the effect it may have on IOP vis-à-vis its hemodynamic properties, using rabbit subjects.

\section{MATERIALS AND METHODS}

Eight health rabbits weighing between 2.80 and $3.30 \mathrm{~kg}$ were used for the study were the Schiotz instruments and materials used for the study were the Schiotz indentation tonometer, $0.5 \%$ ophthalmic lignocaine drops (by Maxheal pharmaceutical, India), ISDN tablets (10mg oral preparation, by Wyeth, batch no. 03G0345, expiring date July, 2006), distilled water, methylated spirit (by Senco, Nigeria), timepiece, and $5 \mathrm{ml}$ hypodermic syringe.

Drug mixture was prepared by dissolving the tablets in clean distilled water. Each $10 \mathrm{mg}$ tablet was dissolved in $\mathrm{lml}$ of distilled water to obtain $10 \mathrm{mg} / \mathrm{ml}$ of ISDN solution. Fresh preparation of ISDN solutions were made daily throughout the days of study in order to maintain its freshness, and to prevent chemical denaturing of the drug compound. Pupillary sensitivity to light and shadow tests were carried out using the pentorch to rule out pupillary and anterior chamber abnormalities, which could affect the IOP value.

The animals were divided into 2 (4 in each group) groups. Group1 (G1) received $1 \mathrm{ml}$ of $10 \mathrm{mg} / \mathrm{ml}$ ISDN solution orally once a day and Group 2 (G2) received $2 \mathrm{ml}$ of $10 \mathrm{mg} / \mathrm{ml}$ ISDN solution orally once a day. Schiotz tonometer was used to determine the IOP of the rabbits before the administration of the ISDN solution. The treatment with ISDN solution lasted only 5 days $\left(D_{1}\right.$ to $\left.D_{5}\right)$ in both groups. The IOP was taken at 15 min interval, for one hour at about similar time for the seven days, although the drugs were not administered on the $6^{\text {th }}$ and $7^{\text {th }}$ day. The intraocular pressure was always measured 3 times at each instance and the average reading recorded. Data was analyzed using the two-way ANOVA with one variable per cell.

\section{RESULTS}

Aninitial increase in IOP was noted for the first quarter of the period the ISDN solution was administered in the two groups, which was accompanied by a sustained decline in the remaining intervals and on withdrawal of treatment, the pressure began an incline towards baseline.

For G1, the mean initial IOP, was $19.5 \mathrm{mmHg}$, which increased to $19.8 \mathrm{mmHg}$ at the first interval, and later on, began reducing subsequently to 19.0, 18.8 , and $18.2 \mathrm{mmHg}$ in the third, fourth, and fifth intervals respectively (fig. 1). A similar trend was observed for $\mathrm{G} 2$.

Statistical analysis showed that there was no significant $(\mathrm{P}<0.05)$ change in IOP for the number of days $\left(D_{1}\right.$ to $\left.D_{7}\right)$ the measurement was taken, when given $1 \mathrm{ml}$ of $10 \mathrm{mg} / \mathrm{ml}$ of the drug solution orally, $\mathrm{F}_{\text {cal }} 1.2<\mathrm{F}_{\text {tab }}$ 1.66. On the other hand, G2 experimental animals showed a statistically significant difference $(\mathrm{P}>0.05)$ for the days the drug was administered. This indicated a significant IOP-increasing effect of the drug on the these animals.

The increase however, was not sustained as the IOP suddenly began declining between $\mathrm{D}_{4}$ and $\mathrm{D}_{5}$ with a peak decline on the 6th day (fig.2). Despite these undulations, it was observed that the variation remained within the physiologic range of IOP, which is between $10-21 \mathrm{mmHg}^{1}$.

\section{DISCUSSION}

The net effect of the drug was a reduction in IOP. Despite the slight initial increases in IOP observed for both groups at about the first quarter following administration of drug, subsequent intervals demonstrated an IOP-lowering effect of the drug. However, it was also observed that the IOP increased significantly with a prolonged 
administration of the drug (see Figs 1 and 2). This may perhaps be resulting from some kind of compensatory mechanisms or additive effects, since this increase was also within physiologic range. The lowering effect observed could possibly have resulted from the NO action of the drug, which is capable of inducing a relaxation of the ciliary muscles leading to decreased trabecular meshwork resistance and thus the alteration in the outflow facility of aqueous humour. There is evidence that the trabecular meshwork has intrinsic contractile elements, which can be relaxed by nitric oxide, leading to increased aqueous humour outflow ${ }^{5,7,10,12,13}$.

Although glaucoma is usually the result of ocular hypertension, glaucoma that does not result from high IOP may equally benefit from vasodilatory effects of NO. Neufeld ${ }^{15}$ posits that the increased presence of endothelial NO synthetase (eNOS) in the vascular endothelia could be neuroprotective in causing vasodilation and increased blood flow in the optic nerve head.

This study has demonstrated the safety of the use of ISDN in the management of congestive cardiac conditions vis-à-vis its ocular effect. It is however not clear by this work, the effect higher doses of this drug may have on the ocular system. Further studies are recommended on the possibilities of using NO donors as future ocular hypotensive agents.

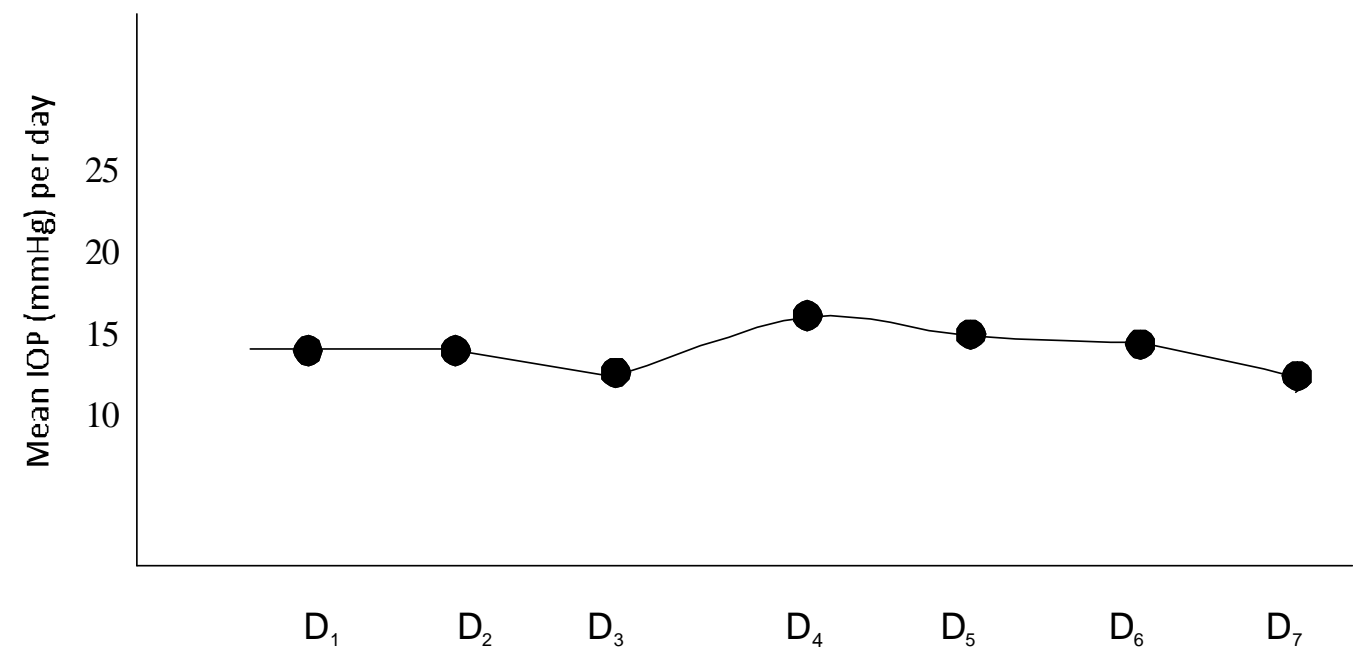

Days of drug administration

FIGURE 1: VARIATION OF THE IOP READINGS WITH DAYS

OF DRUG ADMINISTRATION FOR G1.

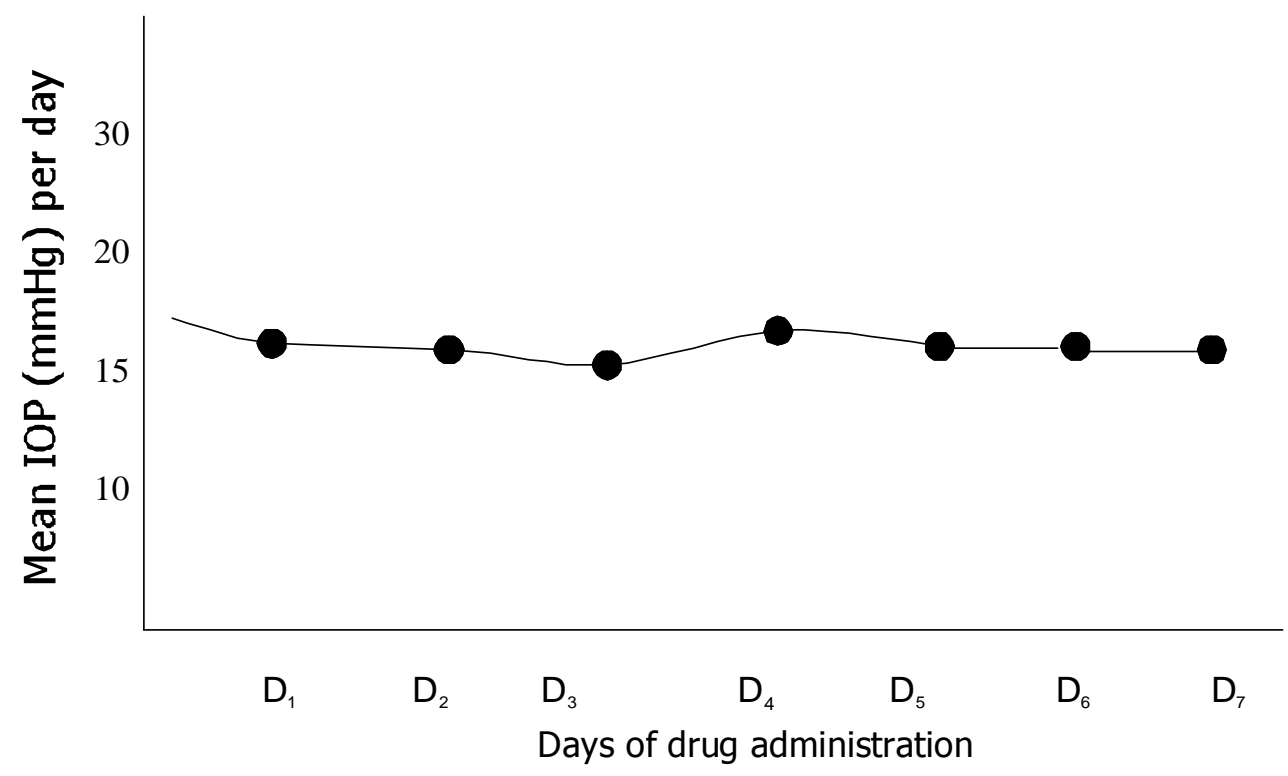

FIGURE 2: VARIATION OF THE IOP READINGS WITH DAYS OF DRUG ADMINISTRATION FOR G2. 


\section{R E F E R E N C E S}

1. Kanski, J. J. (1994): Clinical Ophthalmology. $3^{\text {rd }}$ Edn. Butterworth-Heinemann, Oxford, pp235-76.

2. Hessemer, V. and Schmidt, K. G. (1997): Influences of the vasodilator drug Isosorbide dinitrate on ocular circulation. Arch. Opthalmol, 115:324-7.

3. Grunwald, J. E., Siu K. K., Jacob, S. S. and Dupont, J. (2001): Effect of Sildenafil citrate (Viagra $^{\circledR}$ ) on the Ocular circulation. Am. J. Ophthalmol, 131 (6): 751-5.

4 Katzung, B. G. (2004): Basic and Clinical Pharmacology. $9^{\text {th }}$ Edn. Mcgraw-Hill, New York, pp191-9.

5. Bequet, F., Coutodi Y., and Goureau O. (1997): Nitric Oxide in the eye: Multifaceted roles and diverse outcomes. Surv. Opthalmol, 42:71-82.

6. Haefliger, I. O., Meyer, P., Flammer, J. and Luscher, T. F. (1994): The vascular endothelium as a regulator of ocular circulation: a new concept in Ophthalmology? Sur. Ophthalmol, 39:123-32.

7. Haefliger, I. O. and Dettmann, E. S. (1998): Nitric oxide and endothelium in the pathogenesis of glaucoma: an overview, in Nitric Oxide and endothelium in the pathogenesis of glaucoma. Haefliger I. O. and Flammer J. Edn. Lippincott-Raven Publishers, Philadelphia, pp22-3.

8. Chiou, G. C. Y. (2001): Review: Effect of Nitric oxide on eye diseases and their treatment. J. Ocular Pharm. Ther, 17 (2):18998.

9. Nathanson, J. A. and McKee, M. (1995a): Identification of an extensive system of nitric oxide-producing cells in the ciliary muscle and outflow pathway of the human eye. Invest Ophthalmol. Vis. Sci, 36:1765-73.

10. Tamm, E. R. and Lütjen-Drecoll, E. (1998): Nitric oxide-synthesizing cells in the posterior eye segment in Niric oxide and endothelium in the pathogenesis of glaucoma. Haefliger, I. O. and Flammer, J. Edn. Lippincott-Raven Publishers, Philadelphia, pp68-78.

11. Nathanson, J. A. (1992): Nitrovasodilators as a new class of ocular hypertensive agents. Am. Soc. Pharma. Exptal. Ther, 260 (3): 956-65.

12. Ellis, D. and Nathanson, J. (1998): Nitric Oxide in the human eye: Sites of Synthesis and physiologic actions on Intracular pressure, blood flow, Sodium transport and neural viability in Nitric oxide and epithelium in the pathogenesis of glaucoma. Haefliger I. O. and Flammer J. Edn. Lippincott-Raven Publishers, Philadelphia, pp178-204.

13. Siu, A. W., Leung, M. C., Ho, T. C., Siu, F. K., Ji, J. Z. and Fai So, K. (2002): Total retinal nitric oxide production is increased in IOPelevated rats. Exp. Eye Res, 75:401-6.

14. Wielderholt, M. (1998): Nitric Oxide and endothelium in aqueous humour outflow regulation in Nitric Oxide and endothelium in the pathogenesis of glaucoma. Haefliger I. O., and Flammer J. Edn. Lippincott-Raven Publishers, Philadelphia, pp168-77.

15. Neufeld, A. H., Hermandez, M. R. and Gonzalez, M. (1997): Nitric Oxide Synthetase in the human glaucomatous Optic nerve head. Arch. Ophhalmol, 115:497-503. 